\title{
Defecation delay in patients after lung tumor surgery: a prospective nested case-control study
}

\author{
Jinbo Li ${ }^{1,2,3 \#}$, Tianzhen Yang ${ }^{1,2,3 \#}$, Lijuan Cen ${ }^{1,2,3 \#}$, Yaqing Liang ${ }^{1,2,4}$, Chao Jiang ${ }^{1,2,3}$, Junying Chen ${ }^{1,2,3}$, \\ Xiaomeng Dou ${ }^{1,2,3}$, Wuling Mo ${ }^{5}$, Li Liu ${ }^{1,2,6}$, Yufan Chen ${ }^{1,2,7}$ \\ ${ }^{1}$ State Key Laboratory of Oncology in South China, Guangzhou, China; ${ }^{2}$ Collaborative Innovation Center for Cancer Medicine, Guangzhou, \\ China; ${ }^{3}$ Department of Thoracic Surgery, Sun Yat-sen University Cancer Center, Guangzhou, China; ${ }^{4}$ Outpatient Department Surgery, Sun Yat-sen \\ University Cancer Center, Guangzhou, China; ${ }^{5}$ Cataract Department, Zhongshan Ophthalmic Center, Guangzhou, China; ${ }^{6}$ Nursing Department, \\ Sun Yat-sen University Cancer Center, Guangzhou, China; ${ }^{7}$ Endoscope Center, Sun Yat-sen University Cancer Center, Guangzhou, China \\ Contributions: (I) Conception and design: Y Chen, L Liu; (II) Administrative support: J Li, L Liu; (III) Provision of study materials or patients: J Li, \\ Y Chen; (IV) Collection and assembly of data: T Yang, L Cen, Y Liang, C Jiang, X Dou, W Mo; (V) Data analysis and interpretation: J Li, Y Chen, J \\ Chen; (VI) Manuscript writing: All authors; (VII) Final approval of manuscript: All authors. \\ \#These authors contributed equally to this work. \\ Correspondence to: Li Liu. State Key Laboratory of Oncology in South China, Guangzhou 510060, China; Collaborative Innovation Center \\ for Cancer Medicine, Guangzhou 510060, China; Nursing Department, Sun Yat-sen University Cancer Center, Guangzhou 510060, China. \\ Email: liuli@sysucc.org.cn; Yufan Chen. State Key Laboratory of Oncology in South China, Guangzhou 510060, China; Collaborative Innovation \\ Center for Cancer Medicine, Guangzhou 510060, China; Endoscope Center, Sun Yat-sen University Cancer Center, Guangzhou 510060, China. \\ Email: Chenyf1@sysucc.org.cn.
}

Background: Defecation delay (greater than or equal to 3 days post-surgery) is a common symptom in patients after lung tumor surgery. This study investigated the incidence and relevant risk factors of defecation delay in patients after lung tumor surgery.

Methods: Between October 2019 and March 2020, a prospective nested case-control study was conducted in 80 patients who received lung tumor surgery in the Department of Thoracic Surgery at the Sun Yat-sen University Cancer Center. According to the Rome III criteria for functional constipation and the accepted definitions in the literature, patients with defecation delay time greater than or equal to 3 days post-surgery were classified as the defecation delay group, and the remaining patients were considered the control group. A questionnaire survey was conducted to explore the trait of the stool, defecation time, postoperative activity, diet, and perioperative pain score. Statistical analyses were performed to compare the risk factors affecting defecation time in the two groups.

Results: Out of 80 patients, a total of 44 patients (44/80) experienced defecation delay after the operation. Univariate analysis showed that there were significant differences between the two groups in operation methods $(\mathrm{P}<0.029)$, postoperative stool trait $(\mathrm{P}<0.001)$, difficulty in defecation $(\mathrm{P}<0.01)$, and perioperative pain score $(\mathrm{P}=0.0178)$, suggesting that change of stool characteristics and pain were possible factors causing defecation delay. Multivariate analysis also revealed significant differences between the two groups in the postoperative pain score on the first day post-surgery $(\mathrm{P}=0.03)$.

Conclusions: Defecation delay is a common symptom in patients after lung cancer surgery, and is related to operation method, pain score, and changes in stool characteristics. This study identified that minimally invasive surgery, postoperative pain relief treatment, and health education may play an important role in preventing delayed defecation.

Keywords: Lung surgery; perioperative; constipation; delayed defecation; nested case-control study

Submitted Apr 07, 2021. Accepted for publication Jun 15, 2021.

doi: 10.21037/atm-21-2468

View this article at: https://dx.doi.org/10.21037/atm-21-2468 


\section{Introduction}

Lung carcinoma is a major global health burden and its incidence continues to rise. Surgical resection is the firstline treatment for lung cancer patients (1). However, in the early postoperative period, gastrointestinal peristalsis is weakened due to bed rest, reduced food intake, anesthesia, pain, and long-term tumor effects. All this can result in a delay in defecation time (initial defecation delayed for more than 3 days after surgery) (2). The Rome III criteria is commonly used for the diagnosis of functional constipation (3). However, it does not reflect perioperative constipation accurately. When constipation occurs after surgery, patients may fail to actively report the symptoms to medical staff and thus timely and effective interventions are usually omitted. In a retrospective study of postoperative constipation in children who underwent orthopedic surgery (4), the following three criteria were defined: (I) no stool for more than 3 days post-operation; (II) lower stool volume with abdominal pain and appetite loss; and (III) medical intervention, such as administration of enema, was required. According to the criteria, more than half $(50.9 \%)$ of the children in the study developed symptoms of acute constipation. While numerous other studies have described the symptoms of constipation in patients after orthopedic surgery $(5,6)$, currently, there are no unified diagnostic criteria for perioperative constipation. In clinical practice, the incidence of delayed postoperative defecation is quite high among patients with lung cancer surgery. However, insufficient attention has been directed at clinical diagnosis, intervention, and nursing for delayed defecation. Postoperative constipation can increase the risk of incisional hernia, thrombosis, cardiovascular and cerebrovascular events, and other complications $(7,8)$. In addition, symptoms related to constipation may affect the patient's appetite, normal activities, and rest, which may lead to a delay in recovery. Therefore, it is of great importance to identify and treat postoperative constipation to improve quality of life for patients post-surgery.

This study was an observational study conducted on a pre-determined cohort, using a prospective nested casecontrol design (9). This method is being widely used in medical research. During the follow-up, patients with positive outcomes were included in the study group and patients without positive outcomes formed the control group. The initial defecation time of patients who received lung tumor surgery and their clinical data were analyzed to identify significant risk factors of delayed defecation.
Benefiting from the study design, this study was superior to traditional retrospective studies and minimized potential sources of bias. Both objective data and subjective inspection of patients were collected in our research so the results are very comprehensive that we could find as many significant factors as possible. Compared to previous studies, this investigation showed strong evidence that delayed postoperative defecation was quite common for patients after lung tumor surgery. It provided novel insight into the diagnostic criteria of postoperative constipation and thus enhances our understanding of this common but underestimated problem. This information will contribute to reducing the incidence of postoperative delayed defecation in future clinical practice.

We present the following article in accordance with the STROBE reporting checklist (available at https://dx.doi. org/10.21037/atm-21-2468).

\section{Methods}

\section{Subjects}

From October 2019 to March 2020, 80 patients who were scheduled for lung tumor surgery in the Thoracic Surgery Department were enrolled. The following inclusion criteria were applied: (I) patients with a normal cardiopulmonary, hepatic, and renal operative reserve and who were able to tolerate the procedures; (II) patients with normal oral intake not complicated by other diseases; (III) patients with normal defecation/flatus; (IV) patients with a definite diagnosis of operable lung tumor; and (V) patients who were able to fully understand and agree to participate in the study. All procedures performed in this study involving human participants were in accordance with the Declaration of Helsinki (as revised in 2013). The study protocol was approved by the ethic committee of the Sun Yat-sen University Cancer Center, and informed consent was not required because it was an observational study and no intervention was conducted during entire study.

\section{Study design}

Previous studies have suggested that the incidence of constipation is $4 \%$ in Guangdong, China (10), and 1.4$32.9 \%$ in Asia (11). Mantegazzi et al. reported that $50.9 \%$ of teenagers presented symptoms associated with constipation after receiving orthopedic surgery (4). In order to exclude the subjective experience of patients, in this study, a delay 
of greater than 3 days (3 days not included) was used as the main criteria for diagnosis of constipation. Due to a paucity of information in the literature regarding the postoperative constipation states of lung tumor patients in Guangdong, it was assumed that the incidence of defecation intervals greater than 3 days (3 days not included) among such patients was $32.9 \%$, the highest incidence reported in Asia. If the surgery had no effect on postoperative defecation, the incidence of the delayed defecation (first defecation later than 3 days after surgery) would be the same as the incidence of constipation, which was assumed to be $\mathrm{p} 0=32.9 \%$ (above). We hypothesized that type I error was $\alpha=0.05$, type II error was $\beta=0.1$, and the expected incidence of delayed defecation after surgery was $\mathrm{p}=50.9 \%$ according to Mantegazzi et al. In order to reach a significant result, the sample size was calculated as following:

$\mathrm{n}=\mathrm{p} 0 \times(1-\mathrm{p} 0) \times\{\mathrm{qnorm}(1-\alpha)+$ qnorm $(1-\beta) \times \operatorname{sqrt}[\mathrm{p}$ $\times(1-\mathrm{p}) / \mathrm{p} 0 /(1-\mathrm{p} 0)]\} /(\mathrm{p}-\mathrm{p} 0)^{2}=80$, in which qnorm $(1-\alpha)$ suggested the corresponding $Z$ value of $100 \times(1-\alpha)$ percentile in the standard normal distribution, and similarly for $\operatorname{qnorm}(1-\beta)$.

In the risk factors analysis, patients with the first defecation later than 3 days post-surgery (3 days not included) were allocated into the delayed group, and the other patients were allocated into the control group. Both univariate and multivariate analyses were performed.

\section{Research methods}

Questionnaires were developed based on a review of previous literature and semi-structured clinical interviews for 15 hospitalized lung cancer patients. The questionnaires investigated the pre- and postoperative profiles of the patients. The preoperative profiles included Bristol stool classification (12), defecation frequency, physical activity, and daily intake of food and water. Postoperative questions included the time to first postoperative defecation, stool trait, postoperative activities, water intake, and other clinical information. The questionnaires were uploaded to WeChat, a widely used cellphone social application in China. Patients could fill in the questionnaires by using their cellphone to scan a QR code provided by the nurse in charge. A medical group consisting of two thoracic surgeons, two nurse directors, one head nurse, and one staff nurse assessed the reliability and efficacy of every entry in the questionnaires. This was a purely observational research study and no intervention was performed. Patients were treated in the intensive care unit (ICU) until medical opinion confirmed they were stable for transfer to the thoracic ward [usually on postoperative day (POD) 1]. Nurses would then encourage patients to walk out of bed and urinary catheters were removed. Laxatives were not prophylactically administered until patients presented with constipation-associated symptoms or upon the patient's request. Patients were provided with a liquid diet on POD 1. An intravenous analgesia pump was routinely provided for first 2 days after surgery and extra non-steroidal anti-inflammatory drugs (NSAIDs) or opioids were administered according to the patient's requirements.

\section{Statistical methods}

The data distribution of continuous variables are presented as average values [ \pm standard deviation $(\mathrm{SD})]$, and categorical variables are presented as frequency (\%). A P value less than 0.05 was considered statistically significant.

In univariate analysis, an independent sample $t$-test was performed for comparison of continuous variables that follow a normal distribution, otherwise, a rank-sum test would be used. Chi-square test was used for categorical variables. Since the sample size of this study was 80 , continuity correction was not considered, and Fisher's exact test was used when entries were less than 1 . The pain score during the perioperative period was analyzed by repeatedmeasures analysis of variance. Multivariate analysis was performed using logistics regression. Risk factors with $\mathrm{P}<0.2$ or risk factors considered to be related to defecation delay were included. Statistical software including $\mathrm{R}$ version 4.0.2. Openxlsx, dplyr, stringr, tidyr, ggplot2, ez, reshape2, data.table, broom, dummies, tableone, and other $\mathrm{R}$ language packages were used for statistical analysis and drawing.

\section{Results}

\section{Baseline characteristics of patients}

There were 44 patients whose first postoperative defecation time was greater than or equal to 4 days and they were classified into the delayed group. The remaining 36 patients were included in the control group (Figure 1). A significant difference in surgical methods was found between the delayed group and the control group $(\mathrm{P}=0.029)$, while no statistically significant correlation was observed in the other parameters listed in Table 1. There was no difference in the Bristol classification of preoperative stool trait between the two groups ( $\mathrm{P}=0.20$; Figure 2$)$. However, a significant difference was observed in the Bristol classification of the 


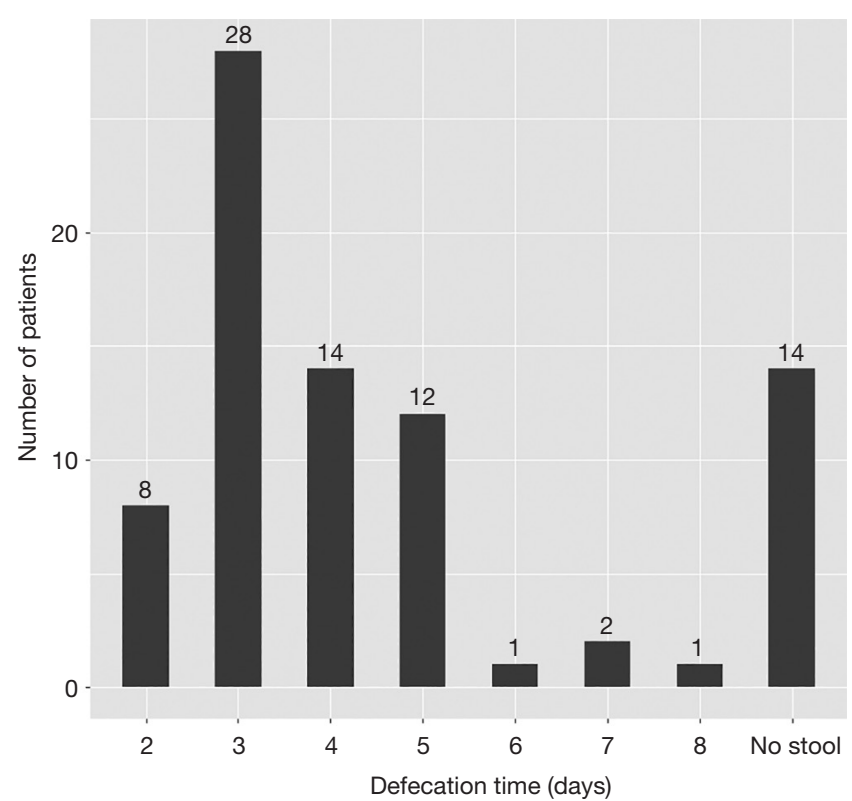

Figure 1 First postoperative defecation time in patients after lung cancer surgery. No stool represents patients who had not defecated at discharge.

Table 1 Demographic and baseline disease characteristics of patients

\begin{tabular}{lccc}
\hline Characteristic & $\begin{array}{c}\text { Delayed } \\
(\mathrm{n}=44), \mathrm{n}(\%)\end{array}$ & $\begin{array}{c}\text { Control } \\
(\mathrm{n}=36), \mathrm{n}(\%)\end{array}$ & $\mathrm{P}$ \\
\hline Age [mean (SD)]/years & $58.34(8.77)$ & $56.25(11.61)$ & 0.362 \\
Body mass index & & & 0.205 \\
Wasting & $1(2.3)$ & $1(2.8)$ & \\
Normal & $31(70.5)$ & $27(75.0)$ & \\
Overweight & $11(25.0)$ & $4(11.1)$ & \\
Obesity & $1(2.3)$ & $4(11.1)$ & \\
Sex & & & \\
Male & $19(43.2)$ & $17(47.2)$ & \\
Female & $25(56.8)$ & $19(52.8)$ & \\
Surgical methods & & & \\
Thoracoscopic & $20(45.5)$ & $26(72.2)$ & \\
Open & $24(54.5)$ & $10(27.8)$ & \\
Pathological type & & & \\
Squamous carcinoma & $7(15.9)$ & $1(2.8)$ & \\
Adenocarcinoma & $29(65.9)$ & $27(75.0)$ & \\
Small cell & $0(0.0)$ & $1(2.8)$ & \\
Others & $8(18.2)$ & $7(19.4)$ & \\
\hline
\end{tabular}

Table 1 (continued)
Table 1 (continued)

\begin{tabular}{lccc}
\hline Characteristic & $\begin{array}{c}\text { Delayed } \\
(\mathrm{n}=44), \mathrm{n}(\%)\end{array}$ & $\begin{array}{c}\text { Control } \\
(\mathrm{n}=36), \mathrm{n}(\%)\end{array}$ & $\mathrm{P}$ \\
\hline T stage & & & $0.918^{\star}$ \\
1a & $10(22.7)$ & $10(27.8)$ & \\
1b & $14(31.8)$ & $8(22.2)$ & \\
1c & $8(18.2)$ & $6(16.7)$ & \\
2 & $4(9.1)$ & $5(13.9)$ \\
3 & $3(6.8)$ & $2(5.6)$ \\
$\mathrm{X}^{\star \star *}$ & $5(11.4)$ & $5(13.9)$
\end{tabular}

N stage

0
1
2

$X^{\star \star \star *}$

Chemotherapy

Hemorrhoids

Preoperative laxative

Oral medicines

\begin{tabular}{lccc} 
Antihypertensive & $12(27.3)$ & $11(30.6)$ & 0.941 \\
Hypoglycemic & $6(13.6)$ & $3(8.3)$ & 0.696 \\
Analgetic & $1(2.3)$ & $1(2.8)$ & 1.00 \\
$\begin{array}{l}\text { Gastrointestinal } \\
\text { prokinetic }\end{array}$ & $1(2.3)$ & $1(2.8)$ & 1.00 \\
Anticoagulation & $0(0.0)$ & $1(2.8)$ & $0.45^{\star}$ \\
Other oral medicines & $8(18.2)$ & $7(19.4)$ & 1.00 \\
Comorbidities & & & \\
Hypertension & $13(29.5)$ & $13(36.1)$ & 0.701 \\
Diabetes & $7(15.9)$ & $4(11.1)$ & 0.769 \\
Heart disease & $3(6.8)$ & $1(2.8)$ & 0.757 \\
$\begin{array}{l}\text { Cerebrovascular } \\
\text { disease }\end{array}$ & $0(0.0)$ & $0(0.0)$ & \\
Liver disease & $3(6.8)$ & $1(2.8)$ & 0.757 \\
Chest surgery & $2(4.5)$ & $3(8.3)$ & 0.816 \\
Abdominal surgery & $4(9.1)$ & $7(19.4)$ & 0.312 \\
Others & $12(27.3)$ & $6(16.7)$ & 0.389 \\
\hline Fisher exact & & & \\
\hline
\end{tabular}

*, Fisher exact test; ${ }^{* *}$, benign or metastatic tumor; ${ }^{* \star *}, \mathrm{X}$ stands for benign or the primary tumor could not be evaluated; ${ }^{* * *}$, lymph node dissections were not performed. SD, standard deviation. 


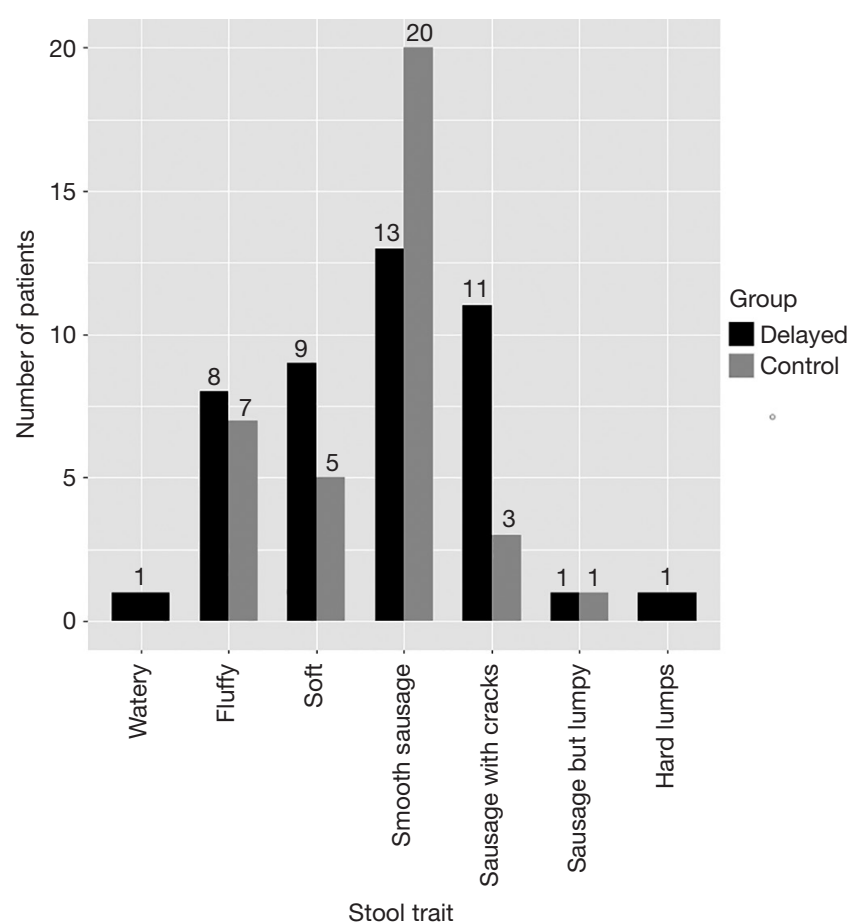

Figure 2 Preoperative stool trait of the patients. There was no statistically significance difference between the two groups $(\mathrm{P}=0.20)$.

postoperative stool trait between the two groups $(\mathrm{P}<0.001$; Figure 3).

\section{Analysis of risk factors for delayed defecation}

Possible risk factors accounting for delayed defecation were analyzed. In univariate analyses, no statistically significant differences were found in preoperative fruit and vegetable intake $(\mathrm{P}=0.94)$ nor water intake $(\mathrm{P}=0.446)$ between the two groups. There were also no significant differences in the frequency $(\mathrm{P}=0.598)$, length $(\mathrm{P}=0.831)$, or intensity $(\mathrm{P}=0.262)$ of preoperative physical activity between the two groups.

However, postoperatively, the two groups differed significantly in difficulty in defecation $(\mathrm{P}=0.01)$, time of first out-of-bed activity $(\mathrm{P}=0.013)$ and perioperative pain score $(\mathrm{P}=0.0178)$. Other postoperative factors including fruit and vegetable intake $(\mathrm{P}=0.937)$, water intake $(\mathrm{P}=0.288)$, frequency $(\mathrm{P}=0.937)$ and intensity $(\mathrm{P}=0.262)$ of physical activity, length of stay in ICU $(\mathrm{P}=0.19)$, time to removal of the urinary catheter $(\mathrm{P}=0.121)$, and use of analgesia showed no statistically significant differences between the two

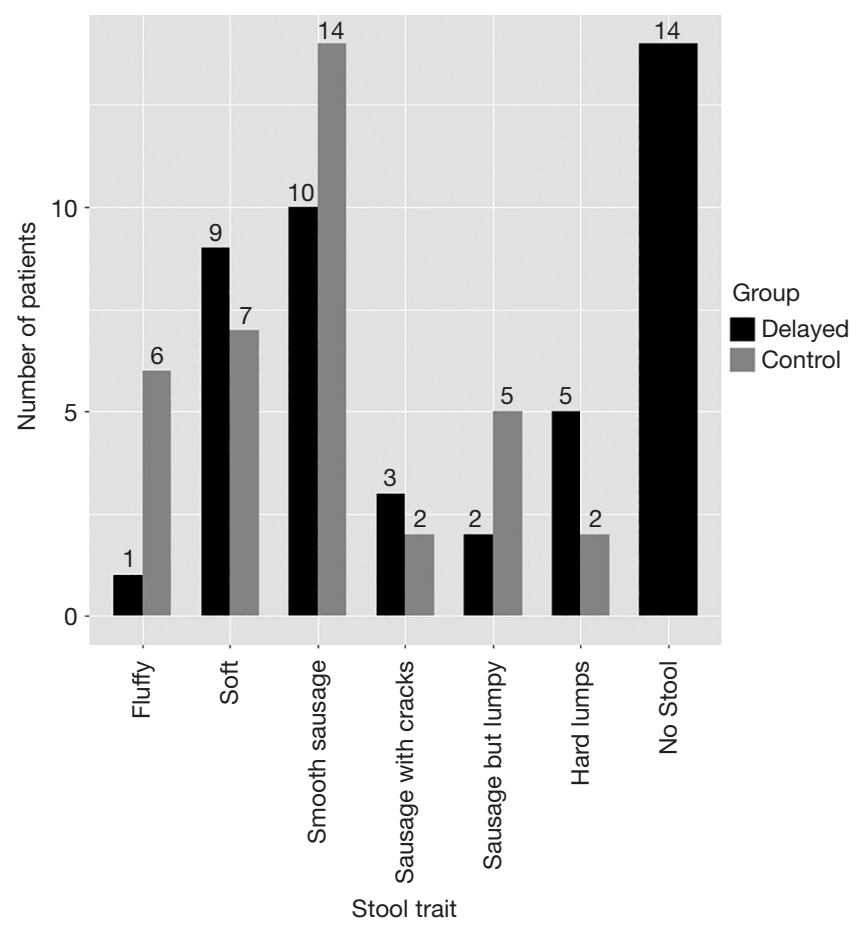

Figure 3 First postoperative stool trait of the patients. No stool indicates the patient had not defecated at discharge, which was around 4 to 7 days post-surgery. The difference between the two groups was significant $(\mathrm{P}<0.001)$.

groups.

On average, it took 2.59 days after surgery for $63.6 \%$ of the patients in the delayed group to request laxatives compared to 0.72 days for $19.4 \%$ of patients in the control group. There were significant differences between the two groups both in the use of laxatives $(\mathrm{P}<0.001)$ and the time to request medical help $(\mathrm{P}<0.001$; Table 2).

In multivariate analyses, the pain score of POD 1 was significantly different between the two groups $(\mathrm{P}=0.03)$, while no significant differences were observed in the remaining factors (Table 3).

\section{Discussion}

In this study, 55.0\% (44/80) of patients experienced delayed defecation after surgery, which exceeded the $32.9 \%$ in the sample size estimation (the incidence of constipation in the population). This suggested that the incidence of postoperative defecation delay among lung tumor patients is higher than that of constipation in the general population. Patients with postoperative constipation 
Table 2 Univariate analysis of the risk factors associated with delayed defecation.

\begin{tabular}{lcc}
\hline Risk factors & $\begin{array}{c}\text { Delayed } \\
(n=44), n(\%)\end{array}$ & $\begin{array}{c}\text { Control } \\
(n=36), n(\%)\end{array}$
\end{tabular}

$\begin{array}{lcc}\text { Preoperative vegetable and fruit intake (times/day) } \\ \geq 3 & 10(22.7) & 7(19.4) \\ 2 & 26(59.1) & 22(61.1) \\ 1 & 6(13.6) & 6(16.7) \\ <1 & 2(4.5) & 1(2.8)\end{array}$

Water intake $(\mathrm{mL})$

0.446

$\begin{array}{lcc}<500 & 4(9.1) & 6(16.7) \\ 500 \text { to } 1,000 & 13(29.5) & 15(41.7) \\ 1,000 \text { to } 1,500 & 17(38.6) & 8(22.2) \\ 1,500 \text { to } 2,000 & 8(18.2) & 5(13.9) \\ \geq 2,000 & 2(4.5) & 2(5.6)\end{array}$

Frequency of physical activity (times/week)

$\begin{array}{llc}0 & 10(22.7) & 4(11.1) \\ 1 \text { to } 2 & 14(31.8) & 13(36.1) \\ 3 \text { to } 5 & 10(22.7) & 9(25.0) \\ \geq 5 & 10(22.7) & 10(27.8)\end{array}$

Length of physical activity (minutes)

0.831

$\begin{array}{lll}<30 & 20(45.5) & 14(38.9) \\ 30 \text { to } 60 & 17(38.6) & 16(44.4) \\ \geq 60 & 7(15.9) & 6(16.7)\end{array}$

Intensity of physical activity

$\begin{array}{lcc}\text { No sweat } & 19(43.2) & 11(30.6) \\ \text { Slight sweat } & 18(40.9) & 22(61.1) \\ \text { Much sweat } & 6(13.6) & 2(5.6) \\ \text { Muscle soreness } & 1(2.3) & 1(2.8) \\ \text { Difficulty in postoperative defecation } & \\ \text { No stool till } & 12(27.3) & 0(0.0) \\ \text { discharge } & 6(13.6) & 7(19.4) \\ \text { Not at all } & 5(11.4) & 9(25.0) \\ \text { Slightly } & 10(22.7) & 11(30.6) \\ \text { Kind of } & 8(18.2) & 7(19.4) \\ \text { Difficult } & 3(6.8) & 2(5.6) \\ \text { Very difficult } & \end{array}$

Table 2 (continued)
Table 2 (continued)

\begin{tabular}{lccc}
\hline Risk factors & $\begin{array}{c}\text { Delayed } \\
(\mathrm{n}=44), \mathrm{n}(\%)\end{array}$ & $\begin{array}{c}\text { Control } \\
(\mathrm{n}=36), \mathrm{n}(\%)\end{array}$ & $\mathrm{P}$ \\
\hline Postoperative vegetables and fruit & & 0.937 \\
Not answer & $17(38.6)$ & $16(44.4)$ & \\
$\geq 3$ /day & $8(18.2)$ & $6(16.7)$ & \\
2/day & $12(27.3)$ & $8(22.2)$ & \\
1/day & $6(13.6)$ & $5(13.9)$ \\
3 to 4/week & $1(2.3)$ & $0(0.0)$ \\
$<3 /$ week & $0(0.0)$ & $1(2.8)$
\end{tabular}

Postoperative water intake $(\mathrm{mL})$

0.288

$\begin{array}{lcc}\text { Not answer } & 17(38.6) & 16(44.4) \\ <500 & 4(9.1) & 5(13.9) \\ 500 \text { to } 1,000 & 17(38.6) & 9(25.0) \\ 1,000 \text { to } 1,500 & 3(6.8) & 5(13.9) \\ 1,500 \text { to } 2,000 & 3(6.8) & 0(0.0) \\ \geq 2,000 & 0(0.0) & 1(2.8) \\ \begin{array}{l}\text { Time to first } \\ \text { postoperative walk }\end{array} & 2.5(0.7) & 2.14(0.54) \\ \text { [mean (SD)]/days } & & \\ \begin{array}{l}\text { Postoperative frequency of physical activity } \\ \text { (times/day) }\end{array} & \\ \geq 3 & 35(79.5) & 28(77.8) \\ 2 & 7(15.9) & 7(19.4) \\ 1 & 1(2.3) & 1(2.8) \\ <1 & 1(2.3) & 0(0.0)\end{array}$

Postoperative intensity of physical activity (cycles

0.262 around the ward)

\begin{tabular}{lccc} 
Bedside & $0(0.0)$ & $2(5.6)$ & \\
$<5$ & $23(52.3)$ & $14(38.9)$ & \\
5 to 10 & $17(38.6)$ & $14(38.9)$ & \\
10 to 20 & $3(6.8)$ & $5(13.9)$ & \\
20 to 30 & $0(0.0)$ & $1(2.8)$ & \\
$\geq 30$ & $1(2.3)$ & $0(0.0)$ & \\
$\begin{array}{l}\text { ICU stay [mean (SD)]/ } \\
\text { days }\end{array}$ & $1.07(0.73)$ & $0.89(0.40)$ & 0.19 \\
$\begin{array}{l}\text { Time of indwelling } \\
\text { urethral catheter }\end{array}$ & $2.48(2.03)$ & $1.92(0.77)$ & 0.121 \\
[mean (SD)]/days & & & \\
\hline
\end{tabular}

Table 2 (continued) 
Table 2 (continued)

\begin{tabular}{|c|c|c|c|}
\hline Risk factors & $\begin{array}{c}\text { Delayed } \\
(n=44), n(\%)\end{array}$ & $\begin{array}{c}\text { Control } \\
(n=36), n(\%)\end{array}$ & $\mathrm{P}$ \\
\hline \multicolumn{4}{|l|}{ Laxative use } \\
\hline Lactulose & $4(9.1)$ & $0(0.0)$ & \\
\hline Enema & $20(45.5)$ & $5(13.9)$ & \\
\hline Lactulose + enema & $4(9.1)$ & $2(5.6)$ & \\
\hline $\begin{array}{l}\text { Time of first laxative } \\
\text { use [mean (SD)]/days }\end{array}$ & $2.59(2.28)$ & $0.72(1.65)$ & $<0.001$ \\
\hline $\begin{array}{l}\text { Hospital stay [mean } \\
(\mathrm{SD})] / \text { days }\end{array}$ & $7.05(3.43)$ & $7.42(4.58)$ & 0.68 \\
\hline \multicolumn{3}{|c|}{ Analgesia use on surgery day } & 0.062 \\
\hline NSAID* & $1(2.3)$ & $6(16.7)$ & \\
\hline \multicolumn{3}{|l|}{ Analgesia use on POD 1} & 0.593 \\
\hline NSAID & 8 (18.2) & $11(30.6)$ & \\
\hline Tramadol & $2(4.5)$ & $2(5.6)$ & \\
\hline Oxycodone & $1(2.3)$ & $2(5.6)$ & \\
\hline Butorphanol & $3(6.8)$ & $0(0.0)$ & \\
\hline NSAID + oxycodone & $1(2.3)$ & $0(0.0)$ & \\
\hline NSAID + tramadol & $2(4.5)$ & $1(2.8)$ & \\
\hline $\begin{array}{l}\text { Tramadol + } \\
\text { oxycodone }\end{array}$ & $1(2.3)$ & $0(0.0)$ & \\
\hline \multicolumn{3}{|l|}{ Analgesia use on POD 2} & 0.945 \\
\hline NSAID & 9 (20.5) & $9(25.0)$ & \\
\hline Tramadol & $1(2.3)$ & $1(2.8)$ & \\
\hline Oxycodone & $5(11.4)$ & $3(8.3)$ & \\
\hline Butorphanol & $1(2.3)$ & $0(0.0)$ & \\
\hline NSAID + oxycodone & $2(4.5)$ & $0(0.0)$ & \\
\hline NSAID + tramadol & $1(2.3)$ & $0(0.0)$ & \\
\hline NSAID (oral) & $1(2.3)$ & $1(2.8)$ & \\
\hline \multicolumn{3}{|l|}{ Analgesia use on POD 3} & 0.182 \\
\hline NSAID & $5(11.4)$ & $8(22.2)$ & \\
\hline Oxycodone & $6(13.6)$ & $2(5.6)$ & \\
\hline NSAID + oxycodone & $4(9.1)$ & $0(0.0)$ & \\
\hline NSAID (oral) & $1(2.3)$ & $1(2.8)$ & \\
\hline \multicolumn{3}{|l|}{ Perioperative pain score } & $0.0178^{\star \star}$ \\
\hline Pre-operation & $0.09(0.36)$ & $0.17(0.70)$ & \\
\hline POD 1 & $6.05(1.74)$ & $4.89(1.51)$ & \\
\hline
\end{tabular}

Table 2 (continued)
Table 2 (continued)

\begin{tabular}{|c|c|c|c|}
\hline Risk factors & $\begin{array}{c}\text { Delayed } \\
(\mathrm{n}=44), \mathrm{n}(\%)\end{array}$ & $\begin{array}{c}\text { Control } \\
(n=36), n(\%)\end{array}$ & $\mathrm{P}$ \\
\hline POD 2 & $5.27(1.98)$ & $4.47(1.87)$ & \\
\hline POD 3 & $4.39(2.14)$ & $3.58(1.78)$ & \\
\hline Discharge & $2.50(1.76)$ & $2.31(1.53)$ & \\
\hline Postoperative appetite & & & 0.107 \\
\hline Not affected & $17(38.6)$ & $16(44.4)$ & \\
\hline Slightly affected & $19(43.2)$ & $18(50.0)$ & \\
\hline Obviously affected & $8(18.2)$ & $1(2.8)$ & \\
\hline Seriously affected & $0(0.0)$ & $1(2.8)$ & \\
\hline Sleep (hours) & & & 0.965 \\
\hline$\geq 10$ & $2(4.5)$ & $2(5.6)$ & \\
\hline 8 to 10 & $8(18.2)$ & $9(25.0)$ & \\
\hline 6 to 8 & $10(22.7)$ & $9(25.0)$ & \\
\hline 4 to 6 & $16(36.4)$ & $11(30.6)$ & \\
\hline 2 to 4 & $7(15.9)$ & $5(13.9)$ & \\
\hline$<2$ & $1(2.3)$ & $0(0.0)$ & \\
\hline
\end{tabular}

*, NSAID was administered by intravenous injection; **, the $P$ value of Levene's test of homogeneity for variance of perioperative pain score was 0.97 , which met the assumption of homogeneity of variance, thus repeated measures analysis of variance was used. SD, standard deviation; ICU, intensive care unit; NSAID, non-steroidal anti-inflammatory drug; POD; postoperative day.

suffered from related symptoms such as abdominal distension, decreased appetite, and many other dysfunctions that affect the patient's nutritional intake, rest, mood, outof-bed activity, and effective cough and expectoration. Postoperative constipation can also cause an increase in abdominal pressure, which further increases the risk of incision dehiscence, incisional hernia, and other surgical complications. It may even cause venous thromboembolism in patients with deep vein thrombosis and lead to lifethreatening adverse events such as pulmonary embolism and other cardio-cerebral vascular events in severe cases. Ultimately, this can affect a patient's recovery and reduced the patient's quality of life. With the development of precision medicine and rapid recovery concepts in the management of cancer patients, it is of vital importance to identify the onset of postoperative constipation through well-formed diagnostic criteria, which will facilitate timely 
Table 3 Multivariate analysis of the risk factors associated with delayed defecation

\begin{tabular}{lccc}
\hline Risk factors & OR $^{*}$ & $\begin{array}{c}95 \% \text { confidence } \\
\text { interval }\end{array}$ & $\mathrm{P}$ \\
\hline Age & 1.03 & $(0.96,1.1)$ & 0.42
\end{tabular}

Surgical method

Open*

Thoracoscopic

$2.25 \quad(0.72,7.36)$

Abdominal surgery

No

Yes

0.51

$(0.1,2.39)$

0.40

Time for postoperative

2.15

$(0.77,6.73)$

0.16

walk

ICU stay

1.60

$(0.52,8.32)$

0.49

Time of indwelling

1.04

$(0.7,2.16)$

0.86

urethral catheter

Analgesia use on surgery day

Not used

NSAID

0.23

$(0.01,2.6)$

0.28

Analgesia use on POD 3

Not used

\begin{tabular}{lccc} 
NSAID & 0.40 & $(0.07,2.09)$ & 0.28 \\
Oxycodone & 1.47 & $(0.24,12.59)$ & 0.69 \\
NSAID + oxycodone & - & $N^{* *}$ & 0.99 \\
NSAID (oral) & 2.24 & $(0.04,378.39)$ & 0.72 \\
Pain score on POD 1 & 1.61 & $(1.08,2.54)$ & 0.03 \\
Pain score on POD 2 & 0.90 & $(0.57,1.37)$ & 0.62 \\
Pain score on POD 3 & 1.23 & $(0.87,1.78)$ & 0.24 \\
Postoperative appetite & & & \\
Not influenced & & & \\
Slightly influenced & 0.83 & $(0.24,2.78)$ & 0.76 \\
Moderately influenced & 4.75 & $(0.40,147.89)$ & 0.27 \\
Severely influenced & $\mathrm{NA}^{* *}$ & $\mathrm{NA}^{* *}$ & 1.00 \\
\hline
\end{tabular}

*, the OR value of the categorical variable was calculated relative to the reference level. The first column of each categorical variable is the reference level; ${ }^{* *}$, the number of patients in the control group was 0 , so the OR and the $95 \%$ confidence interval could not be calculated. OR, odds ratio; ICU, intensive care unit; NSAID, non-steroidal anti-inflammatory drug; POD, postoperative day; NA, not applicable. and efficient interventions.

The current study demonstrated that the main difference between the delayed group and the control group was first reflected in the trait of the stool according to the Bristol classification $(\mathrm{P}<0.001)$ and the effort exerted during the first post-surgery defecation $(\mathrm{P}=0.01)$. This suggested that changes in the shape and trait of stools are important causes leading to delayed defecation and other symptoms related to constipation. Therefore, using hypertonic laxatives such as lactulose, eating a postoperative diet with sufficient fruits and vegetables, and directing patients to drink plenty of fluids may increase the water content of the stools and improve the ease of defecation. At the same time, abdominal massages and medicines that affect gastrointestinal motility may be used to accelerate gastrointestinal peristalsis and reduce the occurrence of delayed defecation. However, the effectiveness of these measures and whether they may be beneficial to all patients, requires further validation in future studies.

Univariate analyses also identified significant differences in the surgical methods $(\mathrm{P}=0.029)$, perioperative pain scores $(\mathrm{P}=0.018)$, and time to first out-of-bed activity $(\mathrm{P}=0.013)$ between the two groups. Multivariate analyses revealed a significant difference in the pain score on day 1 post-surgery between the two groups $(\mathrm{P}=0.03)$. These results may be explained by the choice of surgical method which may affect the pain perception. A patient's pain perception may affect the time to first out-of-bed activity $(\mathrm{P}=0.013)$, appetite $(\mathrm{P}=0.109)$, and sleep $(\mathrm{P}=0.965)$, and may further cause the onset of constipation-related symptoms such as delayed defecation time and decreased stool volume. Conversely, constipation-related symptoms such as abdominal distension and difficulty in defecation may aggravate postoperative pain. Therefore, it was difficult to assess the causal relationship between pain score and defecation delay. This study could only demonstrate a correlation between these factors. In fact, the results suggested that choosing minimally invasive surgery and encouraging patients to perform out-of-bed activities soon after surgery could reduce the incidence of decreased bowel movements and help improve constipation-related symptoms. This is in line with the concept of fast rehabilitation surgery. The difference in pain scores between the two groups on the first POD was both statistically significant in univariate and multivariate analysis, suggesting that among all the risk factors, the degree of post-operative day 1 pain was 
an important factor and predictor of delayed defecation. Furthermore, it suggested that timely treatment of the patient's pain may effectively reduce the onset of delayed bowel movements. However, this requires further verification in future studies.

Although there were no statistical significance differences between the two groups in any of the factors, with the exception of operation method, perioperative pain score, and the time of first out-of-bed walk, the influences of other factors on defecation delay and constipation cannot be disregarded. The significance level of the length of ICU stay $(\mathrm{P}=0.19)$, time of indwelling urethral catheter $(\mathrm{P}=0.121)$, use of analgesia on the surgical day $(\mathrm{P}=0.062)$, and use of analgesia on the third POD $(\mathrm{P}=0.182)$ were very close to the preset significance level $(\mathrm{P}=0.05)$. It is possible that by expanding the research sample size or changing the corresponding evaluation criteria, we may see a statistically significant difference in these factors between the two groups. The significant difference observed between the two groups in the patient's pain score on the first POD suggested that the timely administration of NSAIDs or other analgesics on the surgical day may effectively relieve the pain and reduce the onset of delayed defecation. Conversely, one of the main side effects of opioids in clinical practice is constipation. The main opioids used in the clinical wards during this study were tramadol and oxycodone. As only a few patients needed tramadol and oxycodone, no significant differences were observed between the two types of opioids. However, in clinical practice, the first-line recommendation is still NSAIDs for patients who require analgesic drugs.

A total of $63.6 \%$ of patients with delayed defecation took an average of 2.59 days to request the use of laxatives. In contrast, $19.4 \%$ of the control group took an average of 0.72 days to request laxatives. The differences were both significant in the use of the laxatives $(\mathrm{P}<0.001)$ and the time to use them $(\mathrm{P}<0.001)$. This suggested that patients in the delayed group often requested help from medical staff after delayed defecation or other constipation-related symptoms had occurred. The control group was less troubled by constipation and fewer patients required the use of laxatives. Furthermore, early use of laxatives in the control group suggested that preventative use of laxatives might reduce the occurrence of delayed defecation. However, due to the small number of patients in the control group using laxatives, the practical significance of this result warrants further exploration and verification by randomized controlled studies.
This was an observational study focused on delayed defecation in patients after lung tumor surgery. The postoperative constipation and associated risk factors were explored. An awareness of postoperative constipation and formulating unified standards is important to allow corresponding measures to be adopted in a timely manner. These findings will contribute to the prevention and alleviation of postoperative constipation-related symptoms, and lay the foundations for future clinical studies.

\section{Conclusions}

The incidence of postoperative delayed defecation for lung tumor patients was $55.0 \%$, which significantly exceeded the incidence of constipation in the general population. Patients with delayed defecation had obvious difficulty in defecation, accompanied by changes in stool trait. The patient's perioperative pain perception was significantly related to defecation delay. The use of minimally invasive surgery, early postoperative analgesia, and encouraging patients to engage in out-of-bed activities soon after surgery may help to improve the process of defecation.

\section{Acknowledgments}

Funding: None.

\section{Footnote}

Reporting Checklist: The authors have completed the STROBE reporting checklist. Available at https://dx.doi. org/10.21037/atm-21-2468

Data Sharing Statement: Available at https://dx.doi. org/10.21037/atm-21-2468

Conflicts of Interest: All authors have completed the ICMJE uniform disclosure form (available at https://dx.doi. org/10.21037/atm-21-2468). The authors have no conflicts of interest to declare.

Ethical Statement: The authors are accountable for all aspects of the work in ensuring that questions related to the accuracy or integrity of any part of the work are appropriately investigated and resolved. All procedures performed in this study involving human participants were in accordance with the Declaration of Helsinki (as revised in 2013). The study protocol was approved by the ethic 
committee of the Sun Yat-sen University Cancer Center, and informed consent was not required.

Open Access Statement: This is an Open Access article distributed in accordance with the Creative Commons Attribution-NonCommercial-NoDerivs 4.0 International License (CC BY-NC-ND 4.0), which permits the noncommercial replication and distribution of the article with the strict proviso that no changes or edits are made and the original work is properly cited (including links to both the formal publication through the relevant DOI and the license). See: https://creativecommons.org/licenses/by-nc-nd/4.0/.

\section{References}

1. Zhi X, Shi Y, Yu J. Standards for the diagnosis and treatment of primary lung cancer in China (2015 edition). Chinese Journal of Oncology 2015;37:433-6.

2. Li D, Zhang L, Zhang H. Study on the curative effect of compound clove appetite pastes combined with acupoint application of traditional Chinese medicine in the treatment of postoperative constipation in patients with lung cancer. Shaanxi Traditional Chinese Medicine 2018;39:1375-7.

3. Drossman DA. The functional gastrointestinal disorders and the Rome III process. Gastroenterology 2006;130:1377-90.

4. Mantegazzi LS, Seliner B, Imhof L. Constipation prophylaxis in children undergoing orthopedic surgery: a quasi-experimental study. J Spec Pediatr Nurs 2016;21:109-18.

Cite this article as: Li J, Yang T, Cen L, Liang Y, Jiang C, Chen J, Dou X, Mo W, Liu L, Chen Y. Defecation delay in patients after lung tumor surgery: a prospective nested casecontrol study. Ann Transl Med 2021;9(12):980. doi: 10.21037/ atm-21-2468
5. Lv H, Song Y, Guo X. The hazards and prevention of constipation. Chinese Journal of Preventive Medicine 2019;37:198.

6. Lee TH, Lee JS, Hong SJ, et al. Risk factors for postoperative ileus following orthopedic surgery: the role of chronic constipation. J Neurogastroenterol Motil 2015;21:121-5.

7. Chen Q, Xiao J. Influencing factor analysis of constipation occurrence after thoracolumbar fractures surgery. Nursing Journal of Chinese People's Liberation Army 2014;31:43-6.

8. Sumida K, Molnar MZ, Potukuchi PK, et al. Constipation and risk of death and cardiovascular events. Atherosclerosis 2019;281:114-20.

9. Ye D. Design and analysis of nested case-control study. Journal of Disease Control 2001;5:65-8.

10. Xiong L, Chen M, Chen H, et al. Epidemiological study of chronic constipation in community population in Guangdong Province. Chinese Journal of Digestion, 2004;24:488-91.

11. Sanchez MI, Bercik P. Epidemiology and burden of chronic constipation. Can J Gastroenterol 2011;25 Suppl B:11B-5B.

12. Jaruvongvanich V, Patcharatrakul T, Gonlachanvit $S$. Prediction of delayed colonic transit using Bristol stool form and stool frequency in eastern constipated patients: a difference from the west. J Neurogastroenterol Motil 2017;23:561-8.

(English Language Editor: J. Teoh) 